\title{
Tailoring E-Learning 2.0 to facilitate EU/International Postgraduate Student Needs within the (GVRE) Graduate Virtual Research Environment
}

\author{
Robert Costello, Nigel Shaw \\ Graduate School \\ University of Hull, UK
}

\author{
Darren Mundy \\ Schools of Arts and New Media \\ University of Hull
}

\author{
Barbara Allan \\ Westminster Business School \\ University of Westminster
}

\begin{abstract}
In this paper, we propose a new Dynamic Background Library (DBL) to the Graduate Virtual Research Environment (GVRE). The GVRE was developed as a way of providing a blended learning experience for the development of research and employability skills, and it is informed by the Researcher Development Framework. One of the innovations is the new Dynamic Background Library, which will enable EU/International postgraduate's students to append learning materials to the repository in their own language, using e-learning 2.0. The e-model, in conjunction with the DBL will offer users of the GVRE a more tailored and diversified environment that can offer greater richness of learning activities. This approach will enable research students to have an additional support mechanism when research students are studying for their Postgraduate Certificate in Research Training at the University of Hull, alongside their research degree. Our analysis suggests that there were three factors that influenced the way project participants carried out their learning activities: 1) utilizing the GVRE resources to sustain and enhance their postgraduate journey, 2) relating appropriate resources to research and employability skills development and 3) the increase of student populations from EU/International sector.
\end{abstract}

\section{Introduction}

Learning is an individualistic, complex and sometimes chaotic process. Individuals develop their approaches to learning throughout their careers and develop new strategies as they move from one learning environment to another, such as when a graduate student moves onto postgraduate study. The context of a particular learning experience may have an influence on the way we approach the development of our understanding [1].

Virtual learning environments were originally developed and implemented to cater for groups of students rather than individual students. They are still typically organized around a module or unit of study with a standardized set of resources provided for all students. The ideal learning scenario would be a learning environment personalized to individual requirements [2] as learners adopt and use different learning strategies depending on their context in a given domain topic area.

Although attempts at developing personalized learning systems have worked in the past e.g. Kyprianidou et al., [3], it is still challenging to create such an environment within the context of higher education. The Graduate Virtual Research Environment (GVRE) represents a major step towards the development of an idealized solution to support and guide postgraduate students in their development as researchers.

Existing Learning Management Systems (LMS) [4] such as Moodle, Sakai, and Blackboard all provide facilities and tools to support learning and these typically include: calendar, assessment tools, discussion groups, mail tools, etc... These tools are typically used to support academics in supporting students as they engage with an individual module or programme. Such systems are rarely used in a manner that spans individual modules or programmes. Neither do they link the academic disciplines with the development of employability skills (unless these are included in the learning outcomes of the module).

According to research by Campbell et al., [5] postgraduate students require a balance between the skills needed within the labour market, adaptability, and transferable skills. This cannot always be achieved through standardization of the learning process.

Building on the work of Campbell et al., [5], Vitae [6] indicates that postgraduate students are also required to build upon and develop "the knowledge, intellectual abilities, techniques and professional standards to do research, as well as the personal qualities, knowledge and skills to work with others and ensure the wider impact of research".

The design of the GVRE project was influenced by the Research Councils' Joint Skills Statement (JSS) [7], of what research and transferable skills research students required. The JSS indicated that the QAA Code of practice was to be used to ensure that academic quality and standards were maintained. It also suggested that research and transferable skills development should be embedded in PG research degree programmes. 
There have been attempts in this area to provide additional services for Post-Graduates such as the Hull University Business School's Virtual Graduate School (which provided the basis for the GVRE) [8], the Epigeum video resources [9] and that of the University of Sheffield's Virtual Graduate School (VGS) [10], which provides a repository of video's developed by academics within a variety of disciplines.

The approach taken at the University of Hull acknowledges the development of Epigeum in providing research student educational video resources. However, the Hull project was founded on the recognition of the importance of the research student perspective. It embraced this through the use of student produced and commissioned reflective videos, from different disciplines on a variety of topics which were significant for research students. The rationale behind this approach was to capture the realities of the research process and research students' experiences.

Focus groups held with research students and early career researchers indicated that students wanted to learn about the research journey. The best source for this learning was thought to be learning from other students and more experienced researchers talking about their individual experiences, as opposed to the rather sanitized version of research which is often reported in academic journals or research textbooks. The students also said that ideally they wanted access to these insights through a virtual learning environment i.e. 24/7 access.

The GVRE provides students with access to learning resources (typically video clips but also PowerPoint presentations, personal reflections and statements). These resources provide a personalized approach in enabling students to see other students' views, and how they personally solved their own issues. The resources are prepared for the GVRE by research students who were recruited and trained to complete this activity with an attached monetary stipend. The project manager leads and supports the student resource developers and also ensures the quality of the learning resources.

This is a unique feature of the GVRE project as students are both the creators and users of the learning resources unlike many virtual learning environments where academics or educational developers frequently specify and produce learning resources for student consumption.

At the moment, the GVRE holds over 280 videos covering a diverse range of topics including: qualitative and quantitative research methodologies; advice on the use of commercially available statistical packages; individual researchers experiences with a particular focus on milestones in their research journey such as the upgrade seminar, writing up, and the viva voce; and specific research skills such as writing the literature review, and critical thinking.

The GVRE is also aligned with the University of Hull's Postgraduate Training Scheme. Therefore the different learning resources may be accessed by research students using different pathways. This approach helps to ensure that research students are developing the necessary skills required for employment in the knowledge based economy. It also helps to make the skills development explicit so that students are aware of the development of these skills and their links to employment as they progress through their research journey.

In this paper, we present an approach, which enables personalisation to be developed within existing Virtual Learning Environments.

The main contribution of our work focuses on using a Dynamic Background Library (DBL), to enable EU/International students to incorporate categorised learning materials (Videos/Web-sites) in their own languages and share this with English speaking students via a translation function to improve information retrieval filtering within the GVRE.

The second contribution to the GVRE is the introduction of time-line, which has enabled the provision of research and transferable skills training to be linked directly to the Researcher Development Framework. This approach allows new researchers to conduct a guided search through a rich media repository, belonging to the individual year of study. We believe that providing a personalized learning experience at postgraduate level can actively engage research students, no matter at which stage of their postgraduate journey they are, leading to enhanced research degree completion rates.

The GVRE aims to provide postgraduate researchers with the ability to visually navigate and personalize their learning choices through on-line learning. This process is structured around the Researcher Development Framework (RDF) and it provides a means by which individual students may learn from the experiences of other students and more experienced researchers.

Traditionally, research students achieved their doctorates as a means of entering academic life but this qualification is now used as an entry to many different careers beyond higher education. It is recognized that, in addition to the development of research skills, students also need to develop a range of transferable skills that are linked to employability. The RDF is utilized to provide a professional development framework, which allows students to build upon existing skills or to gain new insight and transferrable skills from tailored courses provided by the University of Hull, through their Postgraduate Training Scheme. The GVRE is used to support research and transferable skills development, in addition to the traditional face-to-face courses. It is 
structured around a number of generic themes. These are video search repository, research skills pathways; training needs analysis, and skill priorities (identifying skills and an e-portfolio application) based on the RDF.

\section{Blended Learning Approach 'GVRE' Background}

The GVRE was established in E-bridge (a University of Hull implementation of the Sakai learning environment) by the University of Hull [8] to provide personalized support to postgraduate students by enhancing their research skills and employability training. It provides an extensive range of rich media resources [8] including: videos of reflections on the experiences of students and staff through their research journey; interactive activities (creative, visual moodboard games, reading lists, search engines, and academic materials); and a Dynamic Background Library (DBL) in which students can add their own materials, resources and experiences. Using a dynamic repository alongside the existing GVRE provides support for the retrieval of learning objects from outside the course content via the internet [9].

\section{The GVRE E-Model Specifications}

To support the diversity and nature of the students an e-model approach was chosen. The GVRE EModel (see Fig. 1) used within this project has been inspired by the Community of Inquiry model by [13] and the simplified representation for the e-learning eco-system (ELES) by [14].

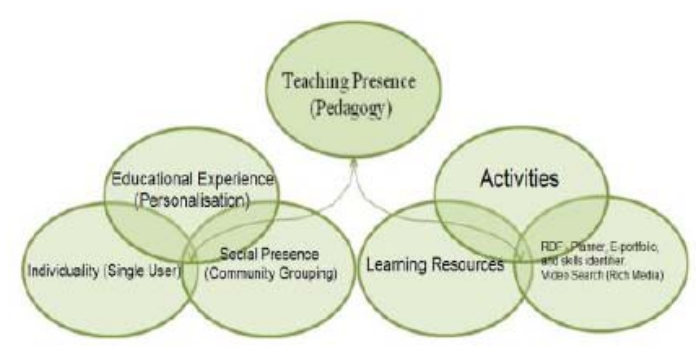

Figure 1. E-Model (Original)

The e-model used within this research can be divided into three main areas:

\section{Teaching Presence (Pedagogical Approach)}

"Teaching Presence is the design, facilitation, and direction of cognitive and social processes for the purpose of realizing personally meaningful and educationally worthwhile learning outcomes” Anderson [13].

The GVRE model uses pedagogical approaches to facilitate the educational experience either from the learner working within a community or individually.
There are a number of pedagogical approaches adopted within Teaching Presence and these are: [11] Social Learning Theory (Video Repository); Informal socio-economic approach for (Rich Media activities and tools); and finally applying Cognitive Behaviorist approaches to resources relating to academic writing skills and pathways.

\section{Learning Activities}

Activities are used within the model to provide different learning resources, based on personal preferences (video, auditory, text and graphics). Learning resources can be used to create pedagogical relationships between activities and personal preferences [11].

Educational Experience, Individuality and Social Presence (Community-grouping)

According to Garrison et al., [15] the educational experience relating to the Community of Inquiry model is used to incorporate students as centre points within their educational process. This particular aspect within the Community of Inquiry model will play a central role in the GVRE e-model because it allows for personalisation to be considered in relation to: a preferred pedagogical learning approach from the tutor and that of UK, EU and International students when used in conjunction with classroom exercises.

Research students engage in a variety of learning communities including membership of research teams based in their department or faculty, wider communities based around the Graduate School or Research Skills Training, and also communities beyond their university such as student research networks and discipline based networks. The GVRE provides access to a different type of community, one where students both produce and utilize the learning resources, which, in themselves, act as a diary or record of individual research journeys. The focus in these records of experiences is on the journey and its highs and lows rather than their contributions to knowledge. In other words, it is the research process and its links to employability that are highlighted in the GVRE.

\section{The Postgraduate Training Scheme (PGTS)}

It is now widely recognised by employers, professional bodies and research funding agencies, that specialist expertise alone is not sufficient preparation either for research or a subsequent career. With this in mind, the University of Hull requires all its postgraduate research students to follow a research training programme relating both to their particular field of study and to generic skills development e.g., Research Methodologies, Project and Time Management skills. 
Within the programme, all research students (fulltime and part-time) registered for a $\mathrm{PhD}$ are required to acquire, during their period of study, a minimum of 60 credits ( 1 credit equating to ten hours of learning, in common with all other Masters level programmes) which will qualify them for the award of the Postgraduate Certificate in Research Training.

The GVRE is used by students and supervisors to identify skills needed for their postgraduate journey. The PGTS is directly linked into the RDF to provide training within specific development domains, create social learning events (like the University of Hull $\mathrm{PhD}$ Experience conference); and to create a friendly vibrant culture. The GVRE provides students with access to a wide range of resources and rich media to assist students with their research journey. The GVRE provides a means of enhancing and supplementing the PGTS and is accessible to students throughout their research careers.

\section{Delivery of the Postgraduate Training Scheme}

The majority of the PGTS taught modules are delivered face-to face throughout the year to campus based students, with a minority of them delivered online. However, the University of Hull also provides Easter and Summer Schools, which are week-long conventions, provided to create a collaborative community network for part time and full-time students. These events are often used by research students to develop new learning resources (e.g. video clips). This means that the ideas shared at these events are available to all research students at all times.

\section{E-learning/Web 2.0}

The concept of Web 2.0 was popularised by O'Reilly and MediaLive International in 2004, but had roots in literature prior to this point. O'Reilly defines the term in a seminal piece 'What is Web 2.0. Design Patterns and Business Models for the Next Generation of Software' O'Reilly, [17] defining seven key principles of what is encompassed by the term 'Web 2.0'. What can be seen as the core principles from other individuals attempting to define the term Web 2.0, are the principles of: 'Web as platform' and 'harnessing collective intelligence'.

The 'Web as platform' principle simply outlines the shift, over the past five to seven years, from previously desktop based application functionality, to web based services and the growth of web based services which allow for the collection of shared resources e.g. Flickr and YouTube. This principle removes previously existing issues with the interoperability of applications across platforms because now, applications run via the web browser which is cross platform compatible.
According to O'Reilly, "Hyper linking is the foundation of the web. As users add new content and new sites, it is bound into the structure of the web by other users discovering the content and linking to it" [17]. Therefore capturing the essence of how users navigate the web and their impressions of web content through mechanisms such as tagging, page rating, and collaborative sharing, can aid users in identifying resources to meet their specific needs.

According to Anderson (2008) Web 2.0 is more than just a web platform it is a service that offers more than just sharing content, tagging, wikis, blogs, and social networking. Web 2.0 is an easy way for people to publish self-generated materials like music, videos and photos.

Also coined alongside Web 2.0 is the term elearning 2.0, which according to Ghali et al., [18],, refers to on-line learning environments that incorporate the idea of the Social Web, making use of technologies such as collaborative authoring tools, rating tools, social identification (e.g. bookmarking) and annotation. According to Hamburg et al., [19] elearning 2.0 uses web-based tools to create new forms of learning materials (e.g. blogs, video sharing repositories, social networking spaces etc...) and to provide different ways of delivering learning materials. Hamburg et al., [19] suggest that incorporating social web concepts into on-line environments can assist with collaborative learning through the use of formal learning, the creation and construction of content and the receiving and giving of feedback through discussion groups.

E-learning 2.0 can be categorised or identified within two particular themes, these are Technology and Social Networking. These link in to the Web 2.0 themes of 'web as platform' and 'harnessing collective intelligence'.

Social Networking, refers to the concept that social interaction plays an important part within elearning 2.0 because it allows students to interact, share ideas, communicate (e-mail, chat, video conference), and use forums to discuss problems. According to Hamburg et al., [19] collaborative learning may provide a useful perspective on learning, knowledge creation and management from a social networking perspective.

It is clear to see that this new generation of elearning 2.0 is focused on applying some form of collaborative community learning through the use of collective intelligence $[18,19]$. The use of e-learning 2.0 within on-line learning will become more frequent and also lead to the incorporation of collaboratively created content in traditional learning environments. These new ideas and concepts have the potential to act as a way of offering a personalised tailored approach to exchange and reuse learning objects; tailored learning activities; and to match content to individual preferences). The next section will focus on the use of Web 2.0, in 
particular that of the Dynamic BackGround Library (DBL) and on using ratings to improve information retrieval filtering within the GVRE to facilitate EU/International Postgraduate student needs within the GVRE.

\section{Dynamic Background library}

In 1999, Dietinger et al., proposed the Dynamic Background Library (DBL) which uses an intelligent algorithm built on the concepts of keyword relevance and user profiles to filter large knowledge bases for data relevant to what the user wishes to learn about. There are however, other e-learning research platforms that have been introduced to support personalization, of which this paper will only mention a few i.e. AdELE, 'Adaptive E-Learning through Eye tracking', iWeaver, 'Towards an interactive web-based adaptive learning environment to address individual learning styles', DEKOR 'dynamic e-learning knowledge repository' and AIPL 'Adaptive Intelligent Personalised Learning' Each of the e-learning environments mentioned above tries to provide personalisation through engaging the learner through sharing comments, resource materials and groupings.

It is well documented within the literature that, using a DBL can improve on-line learning [20] A dynamic repository alongside the existing ebridge VLE would support the retrieval of learning objects from outside the course content using Web 2.0 technologies. It is proposed that using this approach would enable students to write a description in their own language of how relevant the learning material was and where to find it within a category.

According to Mödritscher et al., [20] using a DBL can make the learning experience more personalised. The GVRE through the DBL will enable the learner to have access to teaching materials like video diaries \& reflective accounts, web-sites linkages (qualitative, quantitative; peerreviewed papers and other resources. The learning materials within the GVRE will harness and utilize the 'reusability of web-based learning content' In the GVRE, a filtering mechanism will be used to interrogate the Dynamic Background Library for materials relevant to individual users and in this context the dynamic background library simply acts as a knowledge repository. The DBL Model is illustrated in (see Figure 2)

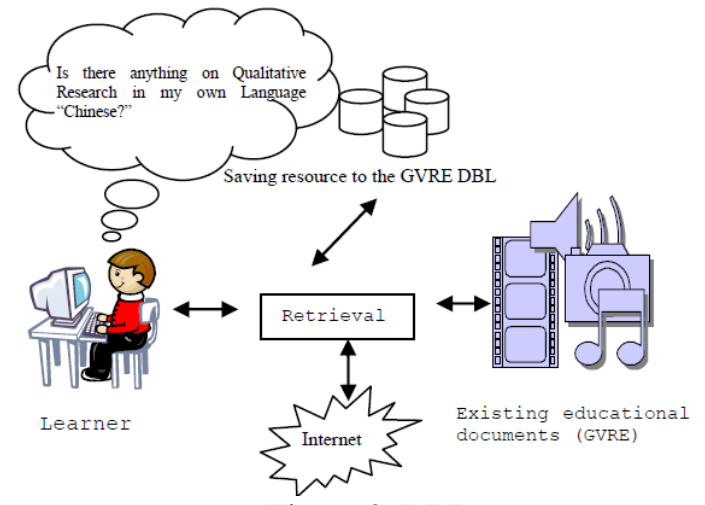

Figure 2. DBL

Figure 2, can be broken into three sections:

1. Learner: EU, International Student who is looking for resources in their native language to assist with their learning journey. Once materials have been found, either on YouTube, or the WWW, then the link can be saved into the Retrieval feature.

2. Retrieval: This is where the learner can add or retrieve existing learning materials from the WWW, or from the repository within the GVRE

3. Existing educational documents (GVRE): This is where the content management software holds the educational resources of the RDF, videos, pathways, etc. Expanding on Figure 2, the interface of the DBL search facility can be seen in Figure 3.

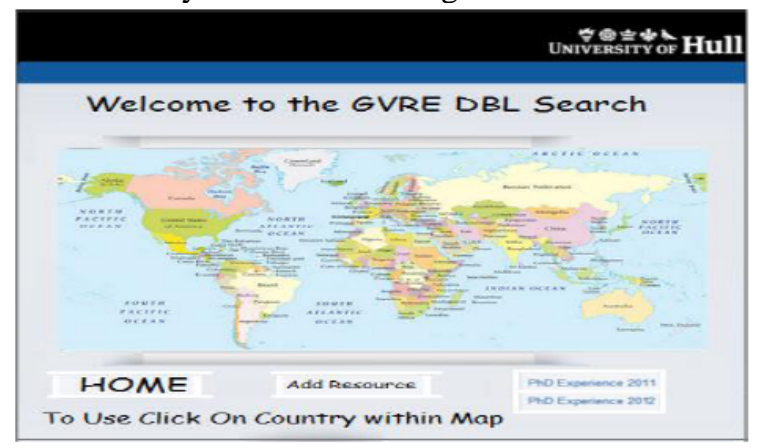

Figure 3. The GVRE DBL Search Facility

Case study example:

Wang from China is currently studying the Summer School Module Qualitative Research Methods to support his research. At the moment he is using resources within the GVRE in English, However, even though Wang is comfortable in English, he would like to add other resources from his own country, produced in his own language, to support not only himself, but other students, both Chinese and from other countries, thus utilizing the Web to broaden the pool of resources available to all.

The GVRE DBL feature will enable him to add new resources (Video, Web-sites and learning materials) which can be shared with other students, 
internationalizing and diversifying the resources made available to research students.

\section{Research Design}

The research design approach adopted within this project involved asking students through focus groups about what features they would like to see to assist the individuals within their learning journey. Out of the focus group response $10 \%$ out of 1000 postgraduates responded that they would like to see if they could add materials they found on-line; a way of using mobile technology to support access to the GVRE from their own country; and on-line courses within the PGTS.

Feedback from the focus group indicates the following responses:

"A good idea, would be that each student can see the materials in their own language”

"Can add materials based in your own language"

"I liked the idea, about uploading resource materials in my own language"

However, the negative side of this approach, which has been recorded, belonging to the focus group would indicate the following:

"Why would international students have a place, where they can upload their own resource materials in their language when studying for a $\mathrm{PhD}$ in England"

"This would discourage them to use English based resources"

"Don't like learning on-line, I have a perfectly good library here at the University"

But looking at the majority of responses belonging to the focus group has indicated that this approach could benefit postgraduates within their learning journey.

Using the focus group and all the participants that took part within the survey will be used to expand on section VI (Previous Research Design) by monitoring usage (On-line tracking tool) and exploring students' experiences through a Mixed Research Methods approach.

The results from this study, which is currently underway, will be reported in 2013. However, at the moment, the snapshot from the preliminary investigation would indicate that the most viewed video topics within the GVRE repository between the months of June, July, and August is: upgrade reports; preparing for upgrades; examination techniques; what to expect; study advice; carrying out literature review and finally getting organized. Using the analytical tools found within YouTube; this will coincide with the end of the academic year. Out of the 280 videos currently being held within the repository, on average each video has been accessed 7 times within the GVRE developmental cycle.

At present, testing has been carried out from a systems point of view. Students will be using the new facility in the new academic session and a study will be carried out on the experiences of the new cohort of research students.

\section{Previous Research design}

The aim of the previous study was to evaluate the research students' experiences of using the GVRE. A mixed methods approach was used to explore the students' experiences using data collected from the on-line tracking tool, as well as an on-line survey.

A total of 80 research students participated in this research, which was conducted from 2011 to 2012. The GVRE was demonstrated to the students, who were given advice on how to use the facilities offered within e-bridge (the virtual learning environment). They then used the GVRE as part of their normal research student experience.

Data was collected using the online tracking tool and through a survey. The online tracking tool enabled data to be collected in relation to the site visits of the individuals, activity within the GVRE and a logging of activity linked to individual resources. This data related to all users registered on the GVRE $(n=1100)$ and this included the 80 students surveyed as part of the study.

Data was also collected using a survey that was sent out via e-mail through the GVRE. In response to our request, 80 students replied and took part in the study.

\section{Previous Results}

\subsection{Research students' journeys into the GVRE}

Using the VLE system tools, we monitored research student usage of the GVRE over an academic year. This enabled us to identify patterns of usage including the impact of interventions such as specific taught modules within the PGTS, induction events, or events designed to raise awareness of the GVRE. We also monitored the students' responses to new resources added to the GVRE. During the time period of the research project, $92 \%$ of the total research student population of 1100 at the University of Hull used the GVRE at least once and 83\% more than 3 times.

During the time from March to July, we introduced a new Human Computer Interface (HCI), which involved: modifying ease of access controls for the interface; greater links to resources; a video search engine; a more effective colour scheme; and captions relating to all videos held within the 
repository, see Fig 4, \& Fig 5 (GVRE interfaces). This tailored approach of removing the traditional LMS features of e-bridge (in conjunction with a new cohort of students), contributed toward a $40 \%$ increase in usage

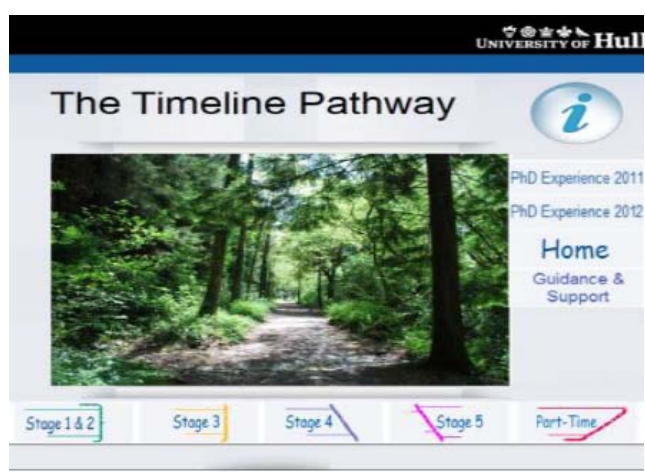

Figure 4. GVRE Interface

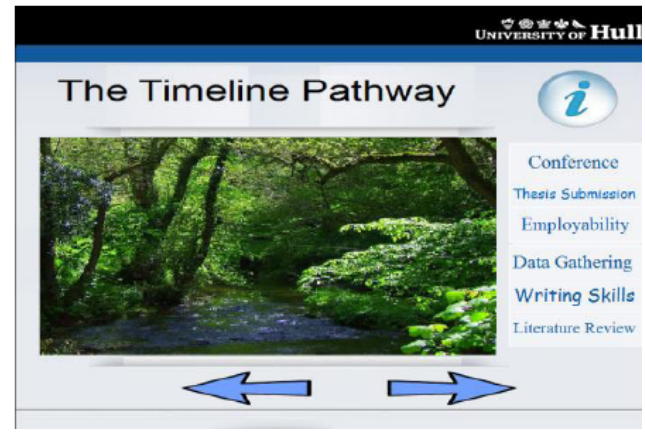

Figure 5. GVRE Interface

As seen within Figure 4 to 5, the whole GVRE elearning environment is graphical driven ensuring that we have broken away from the traditional LMS styles and layouts. This graphical approach adopted by the GVRE provides: ease of use features and flexible navigations links between topic areas.

The data obtained from the online tracking tool indicated that different aspects of the GVRE were used differentially as follows: Video Search Repository 50\%, Pathways and Writing Skills 44\%, Training Needs Analysis, and Prioritise Your Skills $3 \%$ (identifying skills and an e-portfolio application) and the other $3 \%$ is general usage (forums, discussions, announcements, and blogger).

The new approach of tailoring e-learning 2.0 to facilitate a new DBL approach will hopefully increase site traffic through encourage sharing of resources and academic materials.

\section{Research students' responses to the GVRE}

A total of 80 research students took part in the study and completed the questionnaire.

Table 1, presents their feedback on the overall effectiveness of the GVRE in supporting research students. $60 \%$ of students believed that the features and facilitates offered by the GVRE helped them through their research journey. 25\% of the students were satisfied and the other $15 \%$ rated the resources 'fair.'

Table 1. Effectiveness of the GVRE

\begin{tabular}{|l|l|l|}
\hline \multicolumn{3}{|c|}{ Overall, how effective did you find the GVRE? } \\
\hline & Feedback $(\mathrm{N}=80)$ & Percentage $\%$ \\
\hline Excellent & 12 & $15 \%$ \\
\hline Very good & 36 & $45 \%$ \\
\hline Satisfactory & 20 & $25 \%$ \\
\hline Fair & 12 & $15 \%$ \\
\hline Poor & 0 & 0 \\
\hline
\end{tabular}

Table 2, demonstrates the relevance and usefulness of the rich media found within the GVRE. 85\% of the research students believed that the rich media found within the GVRE was useful and very effective in guiding them through their postgraduate journey. The other $15 \%$ of responses found them 'satisfactory' or 'fair'.

Table 2. Effectiveness of the rich media repository

\begin{tabular}{|l|l|l|}
\hline \multicolumn{2}{|l|}{$\begin{array}{l}\text { Overall, how effective did you find the rich media repository in } \\
\text { relation to supporting your postgraduate journey? }\end{array}$} \\
\hline & Feedback $(\mathrm{N}=80)$ & Percentage $\%$ \\
\hline Excellent & 20 & $25 \%$ \\
\hline Very good & 48 & $60 \%$ \\
\hline Satisfactory & 4 & $5 \%$ \\
\hline Fair & 8 & $10 \%$ \\
\hline Poor & 0 & 0 \\
\hline
\end{tabular}

Results from Table 2, indicate that $85 \%$ of the students believed that the research materials stored within the repository was adequate and substantial while supporting their $\mathrm{PhD}$ journey. The feedback from focus group would indicate that they would only use the GVRE when they require a particular topic or field of interest relating directly to their journey.

Deeper analysis of the usage of the GVRE indicated that for some students it was a vital resource e.g. one international student regularly viewed video clips of other students talking about their viva experiences as a means of preparing for the viva and managing her stress levels. Unlike a research supervisor or friend, the GVRE was available 24/7.

\section{Conclusion and future work}

In this paper, we explore the design and usage of the Graduate Virtual Resource Environment (GVRE), developed to provide students with a personalized learning approach. The GVRE provides a tool that enables individual research students to learn from the experiences of other students and to make connections between these journeys and their own endeavors. At the same time, it is designed to help students make connections with the PGTS and also the development of their transferable skills to 
support their future employment, either as an academic, or in another career.

The structure of the GVRE has enabled the provision of research and transferable skills training to be linked directly to the Researcher Development Framework. This approach allows new researchers to conduct a guided search through a rich media repository. We believe that providing a personalized learning experience at postgraduate level can actively engage research students, no matter at which stage of their postgraduate journey they are and so enhance research degree completion rates. The future development of the GVRE will focus on enhancing, a learner centric approach and by focusing on different aspects of the $\mathrm{PhD}$ journey, create a visual timeline, from which students can filter and retrieve materials relating to their current stage of their research degree. This will involve the application of web 2.0 tools and facilities.

Future development of the GVRE will include facilitating the incorporation of Mobile Development (Androids, I-Pads, Smartphone's) and blending Twitter/video uploads into real time communications within discussion boards within the GVRE.

\section{References}

[1] M. Ainscow, T. Booth, and A. Dyson A. "Understanding and developing inclusive practices in schools: a collaborative action research network", Vol 8, Issue 2, International Journal of Inclusive Education, 2004.

[2] R. Costello, and P. D. Mundy. "The Adaptive Intelligent Personalised Learning Environment", in Proc. ICALT, pp.606-610, Ninth IEEE International Conference on Advanced Learning Technologies, 2009.

[3] M. Kyprianidou, S. Demetriadis, and A. Pombortsis. "Designing a Person-Centered Learning Support System". Eighth IEEE International Conference on Advanced Learning Technologies, pp.351-352, 2008.

[4] M.P. Cuéllar, M. Delgado, and M.C. Pegalajar. "A common framework for information sharing in e-learning management systems" [Expert Systems with Applications, Volume 38, Issue 3, Pages 2260-2270, March 2011.

[5] M. Campbell, W. Gibson, A. Hall, D. Richards, and P. Callery. "Online vs. face-to-face discussion in a Webbased research methods course for postgraduate nursing students: a quasi-experimental study." International Journal of Nursing Studies Volume: 45, Issue: 5, Publisher: Elsevier, Pages: 750-759, 2008.

[6] Vitae. "Careers Research and Advisory Centre (CRAC), Realising the potential of researchers", Vitae Researcher Development Framework. 2011, www.vitae.ac.uk (Access Date: 20 Jan, 2012).

[7] Vitae. "Joint Skills Statement” 2012 http://www.vitae.ac.uk/policy-practice/1690/Joint-SkillsStatement.html (Access Date: 15 Jan, 2012).
[8] B. Allan, C. Thomson, and S. Banks., "Networked Learning ten years on: the rise of the Virtual Graduate School" Proceedings of the 7th International Conference on Networked Learning 2010.

[9] Epigeum. “About us” 2012, http://www.epigeum.com/ about-us (Access Date: 15 Dec, 2011).

[10] Virtual Graduate School. "University of Sheffield VGS” http://vgs.group.shef.ac.uk/cms/ (Access Date: 10 Nov, 2011).

[11]Vitae (2012), http://www.vitae.ac.uk/CMS/files/ upload/Vitae-RDF-briefing-Employers-2012.pdf (Access Date: 10 Sep, 2012).

[12] C. Thomson, and B. Allan. "Supporting the Learning and Networking Experiences of Doctoral Students" Proceedings of the 7th International Conference on Networked Learning, 2010.

[13] T. Anderson. "Distance Learning, Social Software's Killer ap?" 17th Biennial Conference of the Open \& Distance Learning Association of Australia, 2005.

[14] V. Chang and C. Guetl. "E-Learning Ecosystem (ELES), A Holistic Approach for the Development of more Effective Learning Environment for Small-toMedium Sized Enterprises (SMEs)". Proceeding of the Inaugural IEEE International Digital, 2005.

[15] .D. R. Garrison, T. Anderson. and W. Archer. "Critical Inquiry in a Text-Based Environment" Computer Conferencing in Higher Education, The Internet and Higher Education 2(2-3): 87-105, 2000.

[16] T., O'Reilly (2007). What Is Web 2.0: Design Patterns and Business Models for the Next Generation of Software. Communications \& strategies, MPRA Paper No. 4578, 2007.

[17] S. Hagemann, C. Letz, and G. Vossen, (2008). Web Service Discovery - Reality Check 2.0, International Journal of Web Services Practices, Vol.3, No.1-2 (2008), pp. 41-46.

[18] F. Ghali, and A. I. Cristea, (2009). MOT 2.0: A Case Study on the Usefuleness of Social Modeling for Personalised E-Learning Systems. In The 14th Int. Conference of Artificial Intelligence in Education (AIED’09) (2009), IOS Press.

[19] I. Hamburg, S. Engert, P Anke, and M. Marin, (2008). IMPROVING E-LEARNING 2.0-BASED TRAINING STRATEGIES OF SMES THROUGH COMMUNITIES OF PRACTICE, Proceedings of the Seventh IASTED International Conference, Web-based Education, March 17-19, 2008 Innsbruck, Austria.

[20] F. Modritscher (2009)., Semantic lifecycles: modelling, application,authoring, mining, and evaluation of meaningful data International Journal of Knowledge and Web Intelligence, Vol. 1, Nos. 1/2, 2009. 